measures, and progressively in a more active way, by putting forward expressions of concern and initiating dispute resolution procedures. Yet as of October 2008, and 13 years after the entry into force of the agreement, 18 countries had not yet established a TBT enquiry point, 10 an SPS enquiry point, and 20 a national notification authority (out of 153 WTO member states).

In the space of just a few years, participation by developing and least developed countries, as well as countries with economies in transition, in the work of the SPS and TBT committees has greatly increased, but more than 80 per cent of dispute resolution procedures are still initiated by developed countries.

To further increase participation and make it more effective, a number of concerns need to be addressed. First, since attending the meetings of the TBT and SPS Committees is costly, supporting the attendance of delegates should remain a priority. However, according to the joint WTO/OECD database, assistance for this purpose only represents 3 per cent of aid-for-trade flows of the "trade policy and regulations" category. This figure is modestly rising thanks to assistance from the Trade Capacity-building Trust Funds.

Secondly, managing the large volume of notifications is a challenge. Taking one example, 947 notifications were submitted in the period from 1 January to 28 September 2007, bringing the total number of SPS notifications to 8,313 by October 2007. Information technology can help in easing the strain on member countries, where there is also scope for successful South-South development assistance.

An important concern for enquiry points is the lack of sufficient means to evaluate the potential impact of new measures for their domestic stakeholders. They may for instance have insufficient understanding about new hazards for which scientific expertise is predominantly based on developed countries' data. Or they may lack surveillance, toxicological and epidemiological data based on their own particular circumstances to challenge notifications of new SPS measures. Training, capacity-building and translation of notifications in the national language are essential for reinforcing participation by developing countries and countries with economies in transition.

Standards-setting institutions: representation of the interests of developing countries and countries with economies in transition

The work of the TBT and SPS committees hinges on standards that are developed in relevant regional and international standards-setting institutions including FAO, CodexAlimentarius Commission, UNECE, World Customs Organization, International Telecommunication Union, International Organization for Standardization (ISO) and International Electrotechnical Commission.

UNECE also develops international trade-related standards and best practice, with the active involvement of business:

- The United Nations Centre for Trade Facilitation and Electronic Business (UN/CEFACT) develops methods to facilitate national and international transactions, through simplifying and harmonizing processes, procedures and information flows.

- The Working Party on Regulatory Cooperation and Standardization Policies develops recommendations on a variety of policy matters relating to technical regulations, standardization, conformity assessment, accreditation, market surveillance and metrology.

- The Working Party on Agricultural Quality Standards develops international commercial quality standards for agricultural produce.

International standards strike a delicate balance between very different appreciations of what is necessary to guarantee quality and safety. A wide scope of stakeholders needs to be active in the standards-setting processes to ensure that the interests of no one group prevail. For this reason, Aid for Trade should include funds for travel to international meetings of specialized standards-setting institutions, awareness-raising about the importance of traderelated standards, training for a core group of highly skilled professionals and increased coordination among national stakeholders to define national interests and needs. Many intergovernmental and non-governmental organizations (including notably ISO) have established technical assistance programmes that include training and direct sponsorship of participation in meetings as well as the production of publications to guide experts that join technical committees. However, this is currently a minor component of technical assistance and available funds for this purpose are scarce. 


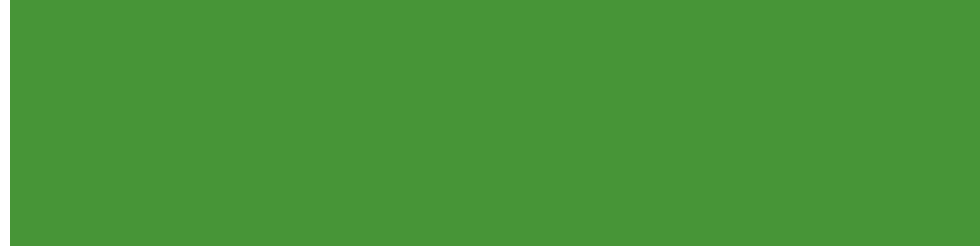

\section{AND ENHANCE MARKET ACCESS}

Next to effective participation in standards-setting activities and competent WTO bodies, compliance with established standards is necessary to ensure smooth trade relations and avoid disruptions that are costly for both buyers and suppliers.

One element of disruption is detentions and rejections at border points, which have increased tremendously in recent years. For example, under the EU Rapid Alert System for Food and Feed, the number of notifications rose almost tenfold from 698 in 1999 to 6,840 in 2006. In the United States, import refusals by the Food and Drug Administration rose from 23,687 in 2002 to 77,260 in 2006. The value or the volume of the detained trade goods is not recorded by these agencies, but one estimate of the value of agro-food trade affected by official product rejections for 2000/2001 was as high as $\$ 3.8$ billion or 0.84 per cent of world exports.

The actual costs of import detentions are likely to be much higher, because costs incurred by the exporter cannot be recouped over and above the value of the lost consignment. Furthermore, in the EU, the exporter will be included in a "rapid alert" list. Increased controls will be set in place in all EU Member States until a certain number of consignments have been cleared by the EU member who initially imposed the alert. Furthermore, although other consignments may eventually not be detained, they will be significantly delayed and large costs will be incurred for import clearance. The combined effect of numerous import detentions - or of an import ban - can in some cases affect an entire export sector, as the example in the box shows.

Investing in compliance is a costly exercise, but expenditures incurred to restore disrupted trade relations are even higher. However, when the right strategy is in place, costs are recouped very rapidly and projects then become self-sustainable. The Lake Victoria case perfectly illustrates how international assistance can help restoring confidence and trade relations.

\section{Exports of fish from Lake Victoria, Uganda}

Starting in 1999, due to several cases of suspected fish poisoning and evidence of inadequatequality standards, the European Union imports of Nile perch fish from the region of Lake Victoria were banned. Uganda and Tanzania, the main exporters of Nile perch from the lake, suffered a tremendous loss; with fish exports dropping by more than 50 per cent as compared to the previous year (see figure 1). A number of fish factories closed or operated under capacity, resulting in redundancy and unemployment. The United Nations Industrial Development Organization (UNIDO) then set up a large technical cooperation project with a total budget of $\$ 4.6$ million with financing from several bilateral donors: Austria, Denmark, Germany, Italy, Japan and the United Kingdom, as well as the United Nations Development Programme. The project established a solid foundation for fish safety so that in 2000 the EU ban could be lifted and new markets opened up, in particular in the United States.

Figure $1 \quad$ Imports of fish from Tanzania and Uganda (millions of dollars)

\section{Outstanding challenges of implementation}

Investing in compliance is a costly exercise. However, it is apparent that when the right strategy is in place, costs are recouped very rapidly, as also happened in the Lake Victoria case. The projects then become self-sustainable thanks to increasing export revenues from existing and new markets. Surveys that have been conducted - particularly by the World Bank and with regard to compliance with agri-food standards - show that in order to increase compliance the priority areas of need are as follows:

- Establishing/revamping laboratory facilities

- Hiring/retaining specialized personnel to carry out tests

- Investing in equipment to ensure cleaning/hygiene

- Establishing or upgrading the institutional mechanisms or competent authorities

- Revising the legal and regulatory framework and regulations

- Upgrading transport and storage facilities.

Traditionally, technical assistance projects place emphasis on the role of the Government and government agencies in projects that aim to increase compliance with trade-related standards. However, in developing and countries with economies in transition many companies or industry associations establish their own testing laboratories because the public administration cannot afford to equip and maintain them. Business has also proven to be very keen to work with foreign partners to resolve 


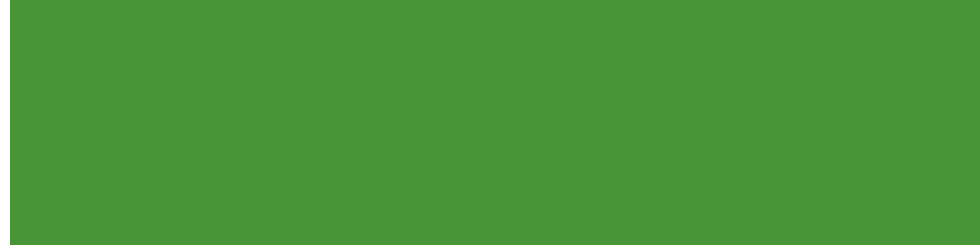

problems of compliance as they arise, and have also been able to join forces with competitors at a national level to establish

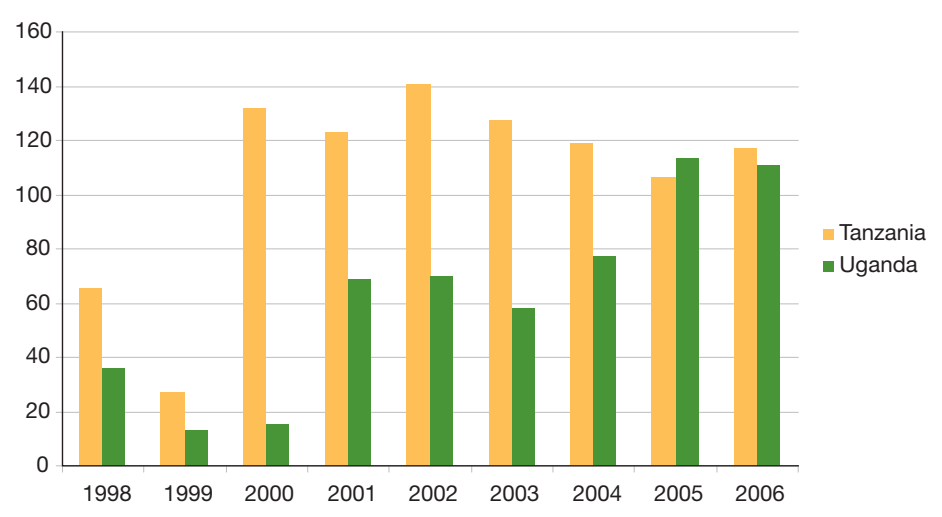

Source: Eurostat

common facilities and exert pressure on local authorities and to remove bottlenecks. Funds directed at public administrations should therefore be complemented by assistance to the business sector, and can be efficiently channelled through industry and exporters' associations.

\section{USING STANDARDS AT A COMPANY LEVEL TO INCREASE COMPETITIVENESS}

Standards are often seen essentially as a means of complying with technical regulations and hence preserving or developing access to markets. Nonetheless, since norms are developed by international experts and incorporate the latest research and know-how, they are also an important means to improve quality and reliability and to climb the value chain to more lucrative niches.

The ability of firms to use product and process standards is also one important element in the choices the transnational corporations (TNCs) make regarding their first and second tier suppliers. These agreements typically involve not only regular and recurrent orders, at pre-agreed prices, but also on-site training and transfer of technological and organizational know-how. On the other hand, those producers that have a mixed record of compliance with international standards will often have no choice but to sell their produce on more volatile international markets, where the TNCs and other smaller clients conclude "on-spot" transactions to fill needs for peak-season orders or unexpected surges in demand.

Finally, the use of standards may contribute to creating valuable strategic partnerships with research institutions. This is an especially important point because achieving one same regulatory objective may require different production processes depending on the technological or climatic conditions of the firm or the farm. For example, if the objective is to achieve a minimum contamination level on consignments of fruit, different production methods may be required depending on where the fruit is grown. The same is true, although it may seem less intuitive, for technical standards as well, because the technology that is used for a given purpose in more technologically advanced economies may not be readily adaptable or may be too costly to integrate. More research activities are therefore needed towards devising practical and cost-effective ways to meet regulatory objectives that take into account the concerns of developing countries and countries with economies in transition.

\section{ASSISTANCE IN THE AREA OF TRADE-RELATED STANDARDS TO DATE}

A number of technical assistance and capacity-building initiatives are under way in the area of trade-related standards. The first Global Aid-for-Trade Review was organized in November 2007 to better understand what kind of assistance is currently being provided in the field of trade and whether it meets the needs of developing countries and countries with economies in transition.

Donor commitments to trade development, during the period 2002-2005, were estimated to average \$21 billion per year and are documented by the WTO/OECD Trade Capacity Building Database. The database is still incomplete, however, because 


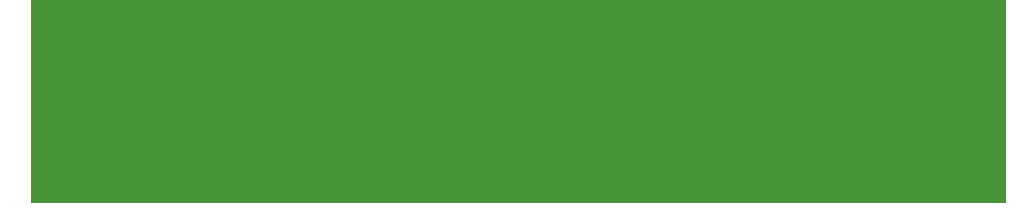

not all donors and recipients fully disclose assistance projects. In particular, World Bank projects are not included in the database, although they play an important role in technical assistance in trade-related standardization matters.

In the database, standards-related technical assistance and capacity-building are mainly captured under theTBT and SPS labels, although capacity-building in standardization matters, as defined for the purposes of this paper, goes beyond SPS and TBT.

There are between 200 and 250 projects on issues related to TBT and SPS in a typical year, accounting on average for 5 per cent of the total number of projects recorded. In monetary value, assistance ranges between $\$ 60$ million and 120 million per year and the percentage is around 5 per cent, but fluctuates markedly from year to year. SPS-related projects account for the majority of both the value and the number of the total (SPS+TBT) projects.

The Trade Capacity Building Database lists 490 projects related to TBTs. Their average size is $\$ 530,000$, but the financial range is wide: 79 projects report very small grants (under $\$ 10,000$ ), while 42 projects have a budget of between $\$ 1$ million and 10 million. Three projects have a budget of over $\$ 10$ million, the largest project being $\$ 17$ million. The European Commission is financing or implementing almost all of the large projects. A large share of the funding for TBT projects recorded in the database is earmarked for building conformity-assessment infrastructure, either by providing equipment for metrology or establishing testing and calibration laboratories.

The share of projects implemented by international organizations in the area of TBT is 18 per cent. The two agencies that are involved the most are UNIDO and the International Trade Centre, followed by OECD, the regional commissions of the United Nations, ISO, UNDP, World Customs Organization and FAO. The rest are implemented directly by bilateral agencies, and in isolated cases, by the beneficiary.

The average size of the projects related to SPS measures, as recorded in the database, is $\$ 455,000$. Out of a total of 890 projects, 236 small projects report grants of below $\$ 10,000$. At the other end of the spectrum, 57 projects have a budget of between $\$ 1$ and 10 million, 6 projects of over $\$ 10$ million, the largest being of 42 million. Again, almost all of the very large projects are financed and/or implemented by the European Commission. Similar to what was noted above for projects in the area of TBT, only 14 per cent of the projects are implemented by intergovernmental organizations, mainly UNIDO and FAO, followed by International Trade Centre, World Organization for Animal Health and WHO.

It is important to note that channelling more of the resources through intergovernmental organizations would ensure that these agencies' expertise could be relayed effectively. In particular, involving those agencies that are active in standards-setting in standards implementation would allow for increased coordination among the stakeholders involved in the various stages of a standard's life. For example, unresolved issues that become apparent in the implementation of a standard could be brought to the attention of the experts when the standard is being revised. And agencies that are active in standards implementation could usefully bring to the projects' design the benefit of a perspective that includes the whole supply chain, thus building up the policy coherence and credibility of the assistance programme. 


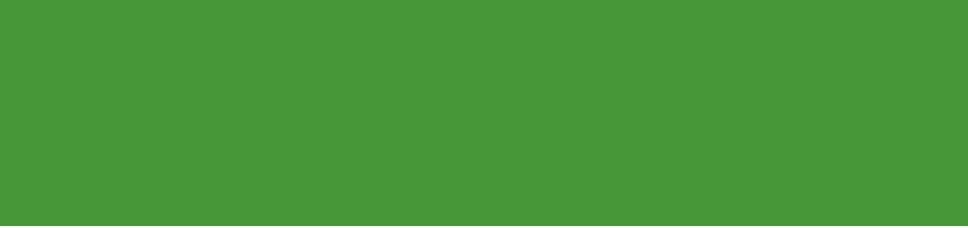

\section{Regional distribution of assistance}

The regional distribution of assistance is set out in figures 2 and 3 . The relatively high share of TBT projects allocated to the countries of South-Eastern Europe, Eastern Europe and Central Asia is related to the exceptional assistance received by new EU Members requested to adopt and implement the acquis communautaire. Additionally, countries with economies in transition have special needs, because they started their transition to a market economy with limited resources in this area. Some of the countries had no national standards-related infrastructure, everything having been previously centralized in locations that after the period between 1988 and 1992 - were no longer within the national borders.

Figure 2 Percentage of total Technical Barriers to Trade-related projects by region, cumulative total 2001-2007 (Total amount: \$243 million)

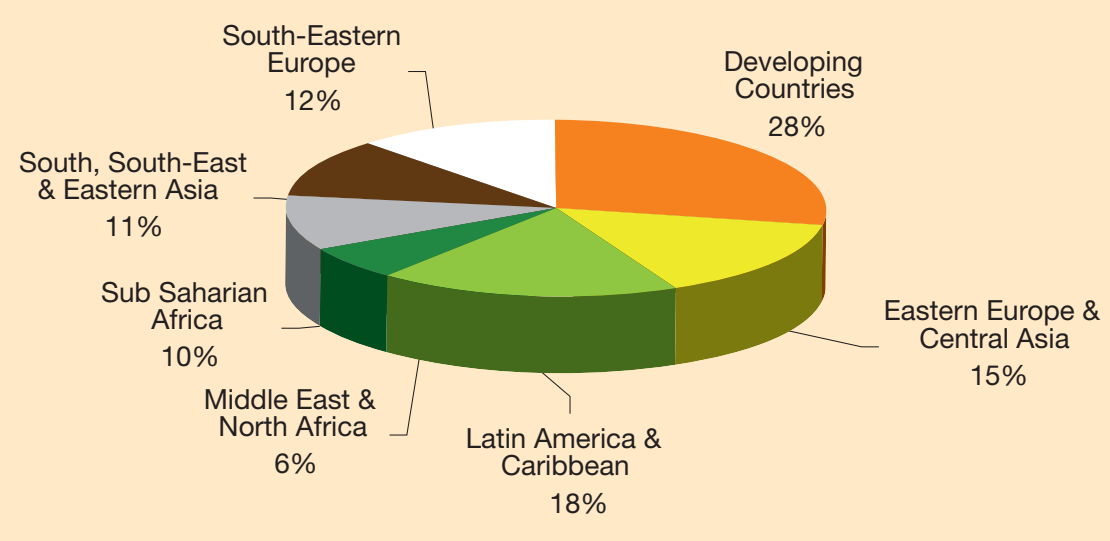

Source: OECD/WTO Trade Capacity Building Database

Figure 3. Percentage of total Sanitary and Phytosanitary Measures donations by region, cumulative total 2001-2007 (Total amount: \$405 million)

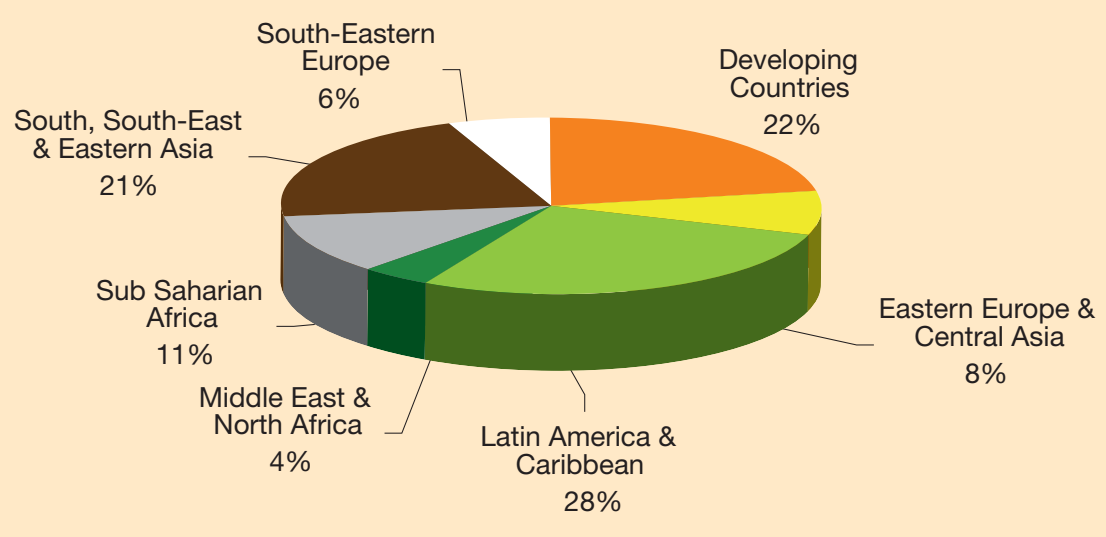

Source: OECD/WTO Trade Capacity Building Database

The regional dimension is of special importance with regard to technical assistance in the area of standards. For example, because of the costs of the technical infrastructure needed to assess compliance with certain technical regulations, it may not be economically viable to set up national laboratories, and a regional approach might offer a feasible alternative.

The regional dimension of technical cooperation and capacity-building in the area of trade-related standards should therefore be maintained and strengthened. All the regional reviews made by WTO, Inter-American Development Bank, Asian Development Bank, African Development Bank or United Nations Economic Commission for Africa (UNECA) have reaffirmed at a high and coordinated level their concern about increasingly stringent SPS and TBT measures in view of their weak capacities to meet international standards and assess conformity through testing, certification and accreditation, and have attracted attention to the need for increased assistance. 


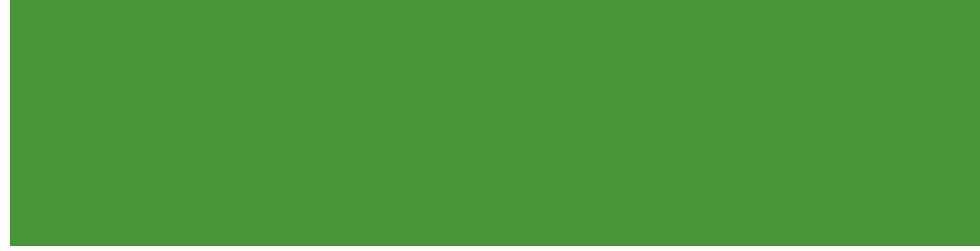

\section{THE WAY FORWARD: REINFORCING PROJECT OWNERSHIP BY BENEFICIARY AND FOSTERING COHERENCE AMONG EXECUTING AGENCIES}

In recent years, a number of efforts have been directed towards assessing and prioritizing needs in the area of standardization. At the institutional level, the WTO/TBT Secretariat conducted a survey on the Second Triennial Review, in 2002, which identified the following priorities, all of which remain relevant:

- Financial and technical support to establish conformity-assessment bodies and the relevant systems

- Technical cooperation to strengthen and upgrade existing laboratories (e.g. through the provision of new equipment, training of staff and study visits)

- Assistance to purchase relevant international standards

- Training in defining measurement uncertainty for calibration and test laboratories

- Training in inspection activities and product certification by means of marks of conformity

- Assistance to formulate a certification scheme that meets WTO requirements, and at the same time protects the interests of consumers and national industry.

More recently, the TBT Committee has also pointed to the need to facilitate the demand and supply of technical assistance and, in 2005, adopted a "Format for the Voluntary Notification of Specific Technical Assistance Needs and Responses". According to WTO itself, however, this voluntary system is not yet being used sufficiently, which may hint at a need for technical assistance activities of an awareness-raising, needs-assessment and training nature.

\section{Coordination among executing agencies}

Much of the development assistance provided over many years to build quality infrastructure has been fragmentary and has not been integrated into national strategies. Countries were receiving different and sometimes contradictory advice on how to set up their technical quality infrastructure effectively and efficiently.

In 2004, a first contribution towards increased coherence was made through the establishment of the Committee on Coordination of Assistance to Developing Countries in Metrology, Accreditation and Standardization. The Committee first enabled Members to exchange information. It then went on to develop a common approach to providing technical assistance for building technical infrastructure and for helping developing countries deal with a number of related challenges. The Committee now recommends that the following be considered:

- A thorough needs assessment of all parts of the economy should be made

- An appreciation that there is no ready-made infrastructure model to be slotted into place; each country must create its own tailor-made solution

- The technical infrastructure should be carefully developed and implemented to ensure sustainability, as there is no such thing as a "quick-fix"

- A clear statement of the resources and finance required should be prepared

- National development of technical infrastructures does not preclude, but may well include, regional approaches, subject to recognizing historical, political and cultural sensibilities.

In the area of SPS, a recent WTO survey of national notification authorities and enquiry points identified the following priorities for technical assistance:

- Raising awareness at the political level and among the public at large

- Increasing coordination among different Ministries

- Mobilizing the relevant private-sector representatives

- Encouraging regional and intergovernmental cooperation, including through mentoring and twinning

- Assisting the enquiry points and national notification authorities in managing the inflow of notifications.

As a result of increasing pressure to improve coherence in responding to developing countries' needs in this area, in 2002 FAO, the World Bank, WHO and WTO established the "Standards and Trade Development Facility" to share information and support capacity-building for developing countries and countries with economies in transition in implementing SPS standards. This Facility has seen a rapid increase in the resources at its disposal, starting from \$1 million in 2002 to \$5 million in 2005 . It is becoming the major clearinghouse as well as an important fund-mobilization scheme.

For least-developed countries, one important source of funding for trade-related technical assistance and capacitybuilding in recent years is the "Integrated Framework for Trade-Related Technical Assistance to Least-developed Countries". 


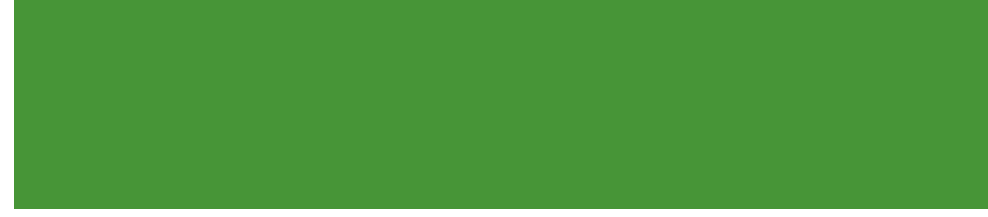

This has, however, only marginally included standards and conformity-related issues and efforts in this area have not been systematic enough to be considered a success.

While it is commendable to ensure coordination among executing agencies, care should be taken to avoid a proliferation of overlapping coordinating mechanisms. Coherence should also be established among executing agencies, not only at the operational level but also at the conceptual level, to ensure that a common message is consistently delivered, irrespective of which agency is executing the project.

\section{Strengthening country ownership}

The country ownership of projects developed in the area of SPS and TBT also needs to be strengthened. In a review of projects related to SPS measures, a World Bank report notes that "a large proportion of assistance in this field by bilateral donors is driven by the "self-interest" or domestic considerations of the donors, such as ensuring that food imports are safe and preventing the spread of [...] pests and animal diseases from their main partners in the developing world". Similar considerations are true for the projects in the area of TBT, where many projects are limited to organizing training to familiarize the officers of the receiving country with the standards and regulatory practices of the donor country. Furthermore many projects are "triggered by crises or imminent trade disruptions and involve reactive and remedial responses". The project regarding the export of fish from Lake Victoria described previously is one clear example (see Box and figure 1).

It is clear that developing countries and countries with economies in transition will benefit much more from projects that aim at assisting them in identifying their own regulatory needs and national priorities and choose international standards that are best adapted to their specific circumstances. For example, some projects provide funding for a country team to engage in training and study tours of countries at a similar level of development, so as to allow a choice from among a variety of approaches that are adapted to their specific conditions, and that can be more easily tailored to the requirements of different export markets. This would result in a level of ownership that will not be attained by simply adopting the regulations in use in the donor's country. It is also key to place emphasis on projects that prevent crises, including by promoting adherence to international standards by large importing countries.

It should also be noted that in sectors in which an agreed international standard has yet to be developed, technical assistance may be a means of influencing international negotiations. In fact, as more authorities become familiar with and apply the regulatory practice of one important country, then gradually this becomes the standard of reference for an entire region. If several donor countries act in this way, positions may become so entrenched that an international agreement on a common standard will be difficult to achieve.

\section{CONCLUSIONS}

As more of the scarce resources devoted to international development assistance are geared towards standards, it is important to define the priorities for action.

First, resources should be devoted to further debate about standards at a national level, including through comprehensive needs assessments, as well as mainstreaming standards in projects that focus on the development of productive capacities in specific sectors. This paper identifies three broad areas of action:

- Reinforcing effective participation in standards-setting and in the relevant WTO institutions

- Increasing compliance with technical regulations

- Furthering the use of standards by business.

To reinforce participation, a policy priority should be for countries to secure funds not only for increased attendance, but also for sustaining active involvement. Countries will need to be assisted in identifying national priorities, in consultation with all the stakeholders. The participation in standards-setting processes should be carefully defined and measured, including by defining "ladders" that document increased involvement, so as to give a visual and tangible dimension to progress made over time by national delegations.

The inclusion of new categories in the Aid for Trade database should not overshadow the need for continued assistance in traditional categories, and in particular in the category of Trade Policy and Regulations, which appears instead increasingly marginalized, not least in the international debate. 
In devising programmes directed at increasing compliance, particular attention should be given to involving the business sector, and its priorities and needs should be better documented and understood. The funds required to restore trade in the aftermath of a crisis are major, but are often recaptured in a relatively short span of time. Aid for trade should aim at preventing and not simply responding to situations of crisis.

Standards are not only a means of securing market access. They have a value in and of themselves because they are developed by international experts and embody the latest technology. They also raise output quality and provide indications to firms on how to better access markets and even to lower costs through the adoption of best practice. However, they also act as a selection device, assisting those producers who are able to adapt to them.

In reviewing the assistance that has been made available to date, it appears that the data are incomplete and do not allow a full appreciation of all the resources that have been invested in the area of assistance for trade-related standardization. Also, too many of the projects seem to aim at facilitating the donor's imports from the country that benefits from the technicalassistance project. Assistance is not tailored to the needs and priorities of recipients. It is also important to increase coherence among efforts underway by different donors and implementing agencies.

The real value added of aid for trade in the area of trade-related standards should be to empower recipient countries by establishing comprehensive national strategies in trade-related standardization matters, in coordination with all the relevant stakeholders, including at the regional level if appropriate. This would allow recipients to make informed choices regarding the regulatory instruments that best meet their development needs and boost active participation in standards-setting institutions, as well as the relevant intergovernmental organizations. 